\title{
ELABORAÇÃO E CARACTERIZAÇÃO FÍSICO-QUIMICA DE BOLO ELABORADO A PARTIR DA CACTÁCEA XIQUEXIQUE
}

\section{PREPARATION AND PHYSICAL-CHEMICAL CHARACTERIZATION OF CAKE ELABORATED FROM CACTACEOUS XIQUEXIQUE}

\author{
Carolaine Gomes dos Reis ${ }^{1}$; Clemilson Elpidio da Silva²; Gabriela Araújo de Oliveira Maia ${ }^{3}$; \\ Cícera Lívia Cavalcante de Lisbôa ${ }^{4}$; Cristiane Ayala de Oliveira ${ }^{5}$
}

DOI: https://doi.org/10.31692/978-65-991061-7-0.21-32

\begin{abstract}
RESUMO
A região semi-árida do Nordeste do Brasil possui em sua fauna uma grande quantidade de cactáceas dentre elas está o xiquexique (Pilosocereus gounellei), que possui sua utilização limitada à alimentação animal. O aproveitamento deste tipo de planta na alimentação humana tem sido constantemente pesquisado, visando buscar uma alternativa prática e viável, o objetivo deste estudo foi elaborar diferentes formulações de bolo utilizando a cactácea xiquexique. Foram desenvolvidas três formulações onde a formulação (F1) foi com $100 \%$ de polpa de xiquexique em substituição a farinha de trigo, a formulação (F2) apresentava $50 \%$ de polpa do xiquexique e $50 \%$ de farinha de trigo, e a formulação (F3) com $50 \%$ de polpa de xiquexique e $50 \%$ de farinha de arroz (sem glúten). Os bolos foram elaborados e posteriormente analisados quanto suas características de: teor de umidade (\%); conteúdo de proteínas (\%); extrato etéreo (\%); teor de cinzas; $\mathrm{pH}$; acidez total titulável em ácido cítrico (ATT) (\%); açúcares redutores em glicose (\%); Açúcares não redutores em sacarose (\%); Açúcares totais em glicose $(\%)$ e Cor objetiva. A cactácea xiquexique apresenta potencial para ser utilizada na elaboração de bolos ou produtos panificáveis. O bolo com $100 \%$ da polpa do xiquexique apresentou-se mais úmido, levemente mais ácido, e com coloração característica da planta. As demais formulações com a adição de farinha de trigo (F2) e arroz (F3) apresentaram características similares, tanto na composição físico-químicas, como em sua aparência. O apelo do uso da farinha de arroz na elaboração do bolo é atrativo, principalmente pelo fato de poder ser consumido por pessoas portadoras da doença celíaca.
\end{abstract}

Palavras-Chave: Cactos; aproveitamento, consumo humano.

\begin{abstract}
The semi-arid region of northeastern Brazil has a large number of cacti in its fauna, among them the xiquexique (Pilosocereus gounellei), which is limited to animal feed. The use of this type of plant in human food has been constantly researched, aiming to find a practical and viable alternative, the objective of this study was to elaborate different cake formulations using xiquexique cactus. Three formulations were developed where formulation (F1) was $100 \%$ xiquexique pulp in substitution of wheat flour, the formulation (F2) had 50\% xiquexique pulp and $50 \%$ wheat flour, and the formulation (F3 ) with $50 \%$ xiquexique pulp

\footnotetext{
1 Acadêmica do Curso Superior de Tecnologia em Alimentos, IF Sertão-PE Campus Salgueiro, carolainetecalimentos@gmail.com

2 Acadêmico do Curso Superior de Tecnologia em Alimentos, IF Sertão-PE Campus Salgueiro, clemilsonelpidio@gmail.com

3 Acadêmica do Curso Superior de Tecnologia em Alimentos, IF Sertão-PE Campus Salgueiro, gabryella_maia@hotmail.com

${ }^{4}$ Docente Doutora do Curso Superior Tecnologia em Alimentos - FATEC/Cariri Ceará liviacali@ hotmail.com

${ }^{5}$ Doutora em Ciência dos Alimentos, Docente do Curso Superior de Tecnologia em Alimentos, IF Sertão-PE Campus Salgueiro, cristiane.ayala@ifsertao-pe.edu.br
} 
and $50 \%$ rice flour (gluten free). The cakes were elaborated and later analyzed as their characteristics of: moisture content (\%); protein content (\%); ethereal extract (\%); ash content; $\mathrm{pH}$; titratable total acidity in citric acid (ATT) $(\%)$; glucose reducing sugars $(\%)$; Non-reducing sugar in sucrose $(\%)$; Total sugars in glucose $(\%)$ and Objective color. The xiquexique cactácea presents potential to be used in the elaboration of cakes or bread products. The cake with $100 \%$ of the xiquexique pulp showed to be more moist, slightly more acidic, and with a characteristic coloration of the plant. The other formulations with the addition of wheat flour $(\mathrm{F} 2)$ and rice $(\mathrm{F} 3)$ presented similar characteristics, both in physicochemical composition and in their appearance. The appeal of the use of rice flour in the preparation of the cake is attractive, mainly because it can be consumed by people with celiac disease.

Keywords: Cacti; use, human consumption.

\section{INTRODUÇÃO}

A região semiárida do Nordeste do Brasil possui uma ampla quantidade de cactos os quais tem grande relevância para a fauna e flora da região, entre as que se destacam está o xiquexique, sendo seu uso, como das demais cactáceas principais, voltada a utilização na alimentação de animais, como forma de subsistência durante a época da seca, que perdura por longo tempo na região (CAVALCANTI; RESENDE, 2007). Por estar restrita ao consumo animal, são escassos os estudos que buscam um aproveitamento deste tipo de planta para o consumo humano., diante disso a indústria de alimentos possui uma grande responsabilidade, uma vez que representa um bom percentual de faturação de quase $15 \%$ e emprega mais de 1 milhão de funcionários. Mesmo conseguindo ter propensões internacionais no setor de produto, requer o aumento no investimento nas áreas de pesquisa e desenvolvimento, ampliando assim a gama de produtos com inovações, seguindo as tendências dos consumidores por produtos saudáveis e práticos no preparo, contribuindo assim o sucesso do empreendimento (GOUVEIA, 2006).

Defini-se por bolo o produto assado, preparado à base de farinhas ou amidos, açúcar, fermento químico ou biológico, podendo conter leite, ovos, manteiga, gordura e outras substancias alimentícias que caracterizam o produto (Resolução da CNNPA - Comissão Nacional de Normas e Padrões para Alimentos, $\mathrm{n}^{\circ} 12$ de 1978).

O bolo vem assumindo papel de destaque dentro do setor de Trigo, sendo explicado pela praticidade, modernização do setor e a utilização de novos agentes de alto desempenho, com também devido ao encarecimento do pão (ADITIVOS E INGREDIENTES, 2008).

Devido sua praticidade e alto consumo, o objetivo deste estudo foi elaborar diferentes formulações de bolo utilizando a cactácea xiquexique (Pilosocereus gounellei), visando agregar valor a um matéria-prima subutilizada, elaborar um produto inovador possibilitar outras formas de aproveitamento a uma matéria-prima que atualmente é restringida apenas ao 
consumo animal.

\section{FUNDAMENTAÇÃO TEÓRICA}

O semiárido nordestino é caracterizado por longos períodos de estiagem, decorrentes de pouca precipitação, alta temperatura e incidência de raios solares diretamente, sendo eles considerados expressivos para a definição do clima e, por conseguinte influencia na formação da vegetação, contudo a vegetação e fauna são habituadas a estes fenômenos. Apresenta uma ampla quantidade de cactos os quais tem grande relevância para a fauna e flora da região, entre as que se destacam está o xiquexique, sendo muito empregada na alimentação de animais, como forma de subsistência durante a época da seca, que perdura por longo tempo na região (PEREIRA JÚNIOR et al., 2015; CAVALCANTI; RESENDE, 2007).

A utilização desta cactácea para uso na alimentação animal ocorre de duas formas, geralmente, a retirada da parte aérea sendo cortada e posteriormente queimada ou atear fogo no cacto em pé sendo o consumo direto no local, a última forma citada provoca danos uma vez que a planta morre, levando assim ao risco de extinção. O xiquexique pode ser caracterizado como um cacto que possui o tronco vertical e ramificações (galhos) laterais distanciados que possuem um encurvamento direcionado ao chão, contendo espinhos de pigmentação verde-opaca; este cacto chega até 3,75 $\mathrm{m}$ de altura e 1,45 a 3,27m de variante para o diâmetro de sua copa, quanto as suas flores são em forma de tubo possuindo a coloração branca (CAVALCANTE; RESENDE, 2006).

A polpa da referida cactácea possui um aspecto que memora ao mamão em seu estado de "vez" (verde), sua utilização na alimentação já é realiza por algumas populações, contudo sem possuir os estudos quanto a composição físico-química; quando modificado para o estado em pó possui um cheiro agradável tendo-se um produto que pode ser inserido na panificação. $\mathrm{Na}$ mesma pesquisa contataram que o xiquexique possui baixa quantidade de ácido ascórbico, logo não pode ser considerado como fonte do referido componente (ALMEIDA et al., 2007).

Chaves e Barros (2015) observaram em suas pesquisas que as cactáceas mais utilizadas por uma população de algumas comunidades do estado do Piauí, sendo elas Cereusalbicaulis, Cereus jamaru, Melocactuszehntneri, Pilosocereus gounellei, Pilosocereus piauhyensis e Tacintainamoena, obtiveram resultados que apontam que as comunidades possuem sabedoria habitual quanto a utilização das referidas na elaboração de produtos como o doce feito a partir do caule, a polpa dos frutos utilizada para sucos e geléias, e as flores utilizadas em cozidos e doces. Sendo que a utilização das cactáceas, hoje em dia está relacionada aos períodos de carência de alimentos, não sendo utilizadas fora dessa 
circunstância.

A indústria de alimentos possui uma grande responsabilidade, uma vez que representa um bom percentual de faturação de quase $15 \%$ e emprega mais de 1 milhão de funcionários. Mesmo conseguindo ter propensões internacionais no setor de produto, requer o aumento no investimento nas áreas de pesquisa e desenvolvimento, ampliando assim a gama de produtos com inovações, seguindo as tendências dos consumidores por produtos saudáveis e práticos no preparo, contribuindo assim o sucesso do empreendimento (GOUVEIA, 2006).

Bolo é definido pela resolução da CNNPA (Comissão Nacional de Normas e Padrões para Alimentos) $\mathrm{n}^{\circ} 12$ de 1978 como sendo o produto assado, preparado à base de farinhas ou amidos, açúcar, fermento químico ou biológico, podendo conter leite, ovos, manteiga, gordura e outras substancias alimentícias que caracterizam o produto.

Os componentes que integram a elaboração do bolo, os ingredientes, possuem papel tecnológico especifico que contribuem para as características do produto acabado. Um quesito que leva a boa aceitação deste produto está na integração de ar a massa, levando ao produto características de leveza, maior volume e fácil mastigação. Além de ser um produto de sabor apreciado possui uma textura macia que facilita no período digestório do produto (SANTOS et al., 2016; SCHMIELE et al., 2011). Para Borges et al. (2006) a importância dos ingredientes utilizados na elaboração do produto está muitas vezes proporcional a quantidade do constituinte adicionado a massa bem como ao tipo de produto elaborado.

As propriedades do bolo podem ser analisadas tanto por instrumentos como sensorialmente, como quanto ao parâmetro de textura, a qual possui bastante importante no produto, como também a cor final da crosta do bolo, sendo o mesmo indicativo de problemas no processo de produção e na formulação do produto, assim possuem falhas aqueles que apresentam crosta de coloração alva ou coloração muito escura (ESTELLER; ZANCANARO JÚNIOR; LANNES, 2006).

Pesquisas vêm sendo conduzidas afim de substituir os ingredientes nas elaborações tradicionais por outros mais saudáveis, mas sem descaracterizar o produto, ou seja, permanecendo com as mesmas características sensoriais do produto tradicional, porém contendo uma redução do teor de lipídeos e valor calórico, e aumento do teor de fibras. Assim, tem-se um produto que vem contentar as exigências dos consumidores, os quais vem se preocupando com a ingestão de alimentos mais saudáveis (MOTA et al., 2011).

O bolo vem possuindo destaque dentro do setor de Trigo, sendo explicado pela praticidade, modernização do setor e a utilização de novos agentes de alto desempenho, com também devido ao encarecimento do pão. A disposição de uma gama de possibilidades de tipo 
de bolo vem sendo notada dentro dos fabricos de bolo, possuindo um crescimento no tipo premium, pequenas porções, preparos isentos de gordura trans, utilização de farinhas integrais, e o controle de qualidade do produto sendo dado a focalização quanto a suavidade e frescor do produto (ADITIVOS E INGREDIENTES, 2008).

\section{METODOLOGIA}

O estudo foi realizado no Laboratório de Produtos de Origem Vegetal (LAPOV), no departamento de Tecnologia em Alimentos, do Instituto Federal de Educação, Ciências e Tecnologia do Sertão Pernambucano, Campus Salgueiro. Foram utilizados os galhos do xiquexique coletados na fazenda da instituição.

As cactáceas foram despojadas dos espinhos, lavadas em água corrente e submetidas à sanitização durante 15 minutos em solução clorada a 200 ppm, lavadas em água corrente novamente e secas com auxílio de panos limpos. O xiquexique, foi cortado e separado de seu pâncreas armazenador de água, as massas obtidas dos galhos foram picadas e processadas em liquidificador industrial. Após a homogeneização da massa foi reservada até a adição dos ingredientes secos.

Os ingredientes secos foram adquiridos no mercado local de Salgueiro-PE, observando-se sempre as condições de armazenamento e prazo de validade. Como formulação base para elaboração dos bolos utilizou-se a reportada por Silva et al. (2010), com algumas adaptações. Foram desenvolvidas três formulações onde a formulação (F1) foi a com 100\% de polpa do xiquexique em substituição a farinha de trigo, a formulação (F2) apresentava $50 \%$ de polpa do xiquexique e $50 \%$ de farinha de trigo, e a formulação (F3) com $50 \%$ de polpa de xiquexique e $50 \%$ de farinha de arroz (sem glúten). A elaboração procedeu-se conforme o fluxograma da figura 1.

Figura 1 - Fluxograma da Elaboração do bolo adicionado da polpa de xiquexique.

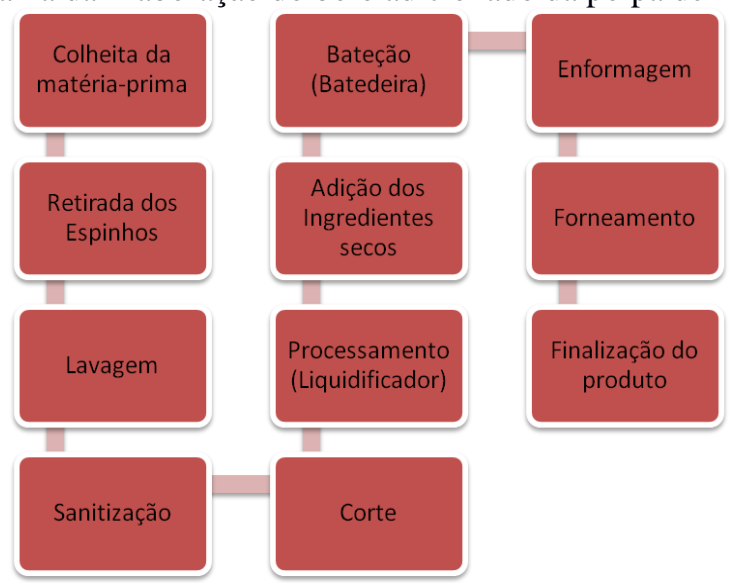

Fonte: os próprios autores 
Após a elaboração dos produtos, foram procedidas as análises físico-químicas, objetivando caracterizar os produtos elaborados. Para o preparo das amostras foram tomadas aproximadamente $50 \mathrm{~g}$ de cada formulação, cada amostra foi individualmente homogeneizada e as porções analisadas com relação:

Teor de umidade: a umidade foi determinada através do método gravimétrico, utilizando a secagem direta em estufa a $105^{\circ} \mathrm{C}$ (IAL, 2008);

Conteúdo de proteínas: o conteúdo de proteína foi conforme o método Kjeldhal (fator de conversão: 5,7) (IAL, 2008);

Extrato etéreo: para a extração de lipídeos utilizou-se o método de Folch (Folch et al. 1957);

Teor de cinzas: os conteúdos de cinzas foram determinados através da incineração à temperatura de $550^{\circ} \mathrm{C}$ em forno mufla (IAL, 2008);

pH: o $\mathrm{pH}$ foi determinado pelo método do potenciométrico, através de medidor digital da marca HANNA modelo 21, previamente calibrado com soluções tampão de pH 4,0 e 7,0; os resultados foram expressos em unidades de $\mathrm{pH}$ (IAL, 2008).

Acidez total titulável em ácido cítrico (ATT): a acidez total titulável (ATT) das amostras foram determinadas através do método acidimétrico do IAL (2008), onde as amostras foram tituladas com solução padronizada de $\mathrm{NaOH} 0,1 \mathrm{~N}$, sendo os resultados expressos em porcentagem de ácido cítrico.

Açúcares redutores em glicose: foram determinados pela técnica da titulometria de Fehling em aquecimento, de acordo com a metodologia preconizada em IAL (2008).

Açúcares não redutores em sacarose: foram determinados pelo método baseado na multiplicação da diferença entre as porcentagens de açúcares totais e açúcares redutores com o fator 0,95, seguindo a metodologia descrita no IAL (2008).

Açúcares totais em glicose: foi utilizada a técnica da titulometria com solução de Fehling com aquecimento, de acordo com IAL (2008).

Cor objetiva: a avaliação objetiva da cor final dos bolos foi conduzida com o uso de um colorímetro. Para o cálculo dos índices de cor, foi estabelecido o iluminante $\mathrm{C}$, o ângulo de $10^{\circ}$ para o observador e o sistema de cor CIELAB. As amostras de bolo foram dispostas em uma placa de Petri de $15 \mathrm{~mm}$ de altura até ter sido preenchida por completo e os índices de cor $\mathrm{L}^{*}, \mathrm{a}^{*} \mathrm{e} \mathrm{b}^{*}$ foram obtidos considerando-se o valor médio de seis leituras realizadas em diferentes pontos da superfície.

Os índices de saturação $\left(\mathrm{C}^{*}\right)$, ângulo de tonalidade $\left(\mathrm{h}^{*}\right)$ e diferença global $\left(\Delta \mathrm{E}^{*}\right)$ foram calculados pelas seguintes fórmulas: 


$$
\begin{gathered}
\mathrm{C}^{*}=\left(\mathrm{a}^{*} 2+\mathrm{b}^{*} 2\right) 1 / 2 ; \\
\mathrm{h}^{*}=\tan -1\left(\mathrm{~b}^{*} / \mathrm{a}^{*}\right) ; \mathrm{e} \\
\Delta \mathrm{E}^{*}=\left[\left(\mathrm{L}^{*}-\mathrm{L}^{*} \mathrm{ref}\right) 2+\left(\mathrm{a}^{*}-\mathrm{a}^{*} \mathrm{ref}\right) 2+\left(\mathrm{b}^{*}-\mathrm{b}^{*} \mathrm{ref}\right) 2\right] 1 / 2 .
\end{gathered}
$$

Para a análise estatística foi adotado um delineamento inteiramente casualizado com três formulações (F1, F2 e F3), todas as análises foram realizadas em triplicata. Para análise das características físico-químicas analisadas empregou-se a análise de variância (ANOVA) e o teste de Tukey para comparar as médias a um nível de 5\% de probabilidade. As análises foram realizadas utilizando-se o programa SASM-Agri (CANTERI et al., 2001).

\section{RESULTADOS E DISCUSSÃO}

Os resultados obtidos para a composição dos bolos elaborados com a polpa da

\begin{tabular}{|c|c|c|c|}
\hline & F1 & $\mathbf{F 2}$ & F3 \\
\hline & $39,72^{\mathrm{a}}$ & \pm & \\
\hline \multirow[t]{2}{*}{ Umidade (\%) } & 2,27 & $30,88^{b} \pm 0,49$ & $22,25^{\mathrm{c}} \pm 0,66$ \\
\hline & $7,34^{\mathrm{b}}$ & \pm & \\
\hline \multirow[t]{2}{*}{ Proteína $(\%)$} & 1,18 & $8,13^{\mathrm{a}} \pm 0,87$ & $7,10^{b} \pm 0,25$ \\
\hline & $8,74^{\mathrm{a}}$ & \pm & \\
\hline \multirow[t]{2}{*}{ Lipídeos (\%) } & 0,48 & $9,31^{\mathrm{a}} \pm 0,71$ & $8,67^{\mathrm{a}} \pm 0,63$ \\
\hline & $2,65^{\mathrm{a}}$ & \pm & \\
\hline \multirow[t]{2}{*}{ Cinzas (\%) } & 0,02 & $2,78^{a} \pm 0,02$ & $2,51^{\mathrm{a}} \pm 0,01$ \\
\hline & $8,85^{\mathrm{a}}$ & \pm & \\
\hline \multirow[t]{2}{*}{ Açúcares Totais (\%) } & 0,24 & $9,14^{\mathrm{a}} \pm 0,21$ & $8,99^{a} \pm 0,28$ \\
\hline & $3,22^{\mathrm{a}}$ & \pm & \\
\hline \multirow[t]{2}{*}{ Açúcares Redutores (\%) } & 0,00 & $3,35^{\mathrm{a}} \pm 0,00$ & $3,16^{\mathrm{a}} \pm 0,00$ \\
\hline & $5,76^{\mathrm{a}}$ & \pm & \\
\hline \multirow[t]{2}{*}{ Açúcares Não Redutores (\%) } & 0,24 & $5,80^{\mathrm{a}} \pm 0,22$ & $5,83^{a} \pm 0,28$ \\
\hline & $7,33^{\mathrm{a}}$ & 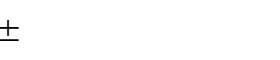 & \\
\hline \multirow[t]{2}{*}{ pH } & 0,14 & $7,46^{\mathrm{a}} \pm 0,43$ & $7,40^{\mathrm{a}} \pm 0,99$ \\
\hline & $5,20^{\mathrm{b}}$ & \pm & \\
\hline Acidez Titulável (\% de ácido cítrico) & 1,29 & $6,77^{\mathrm{a}} \pm 2,25$ & $6,75^{\mathrm{a}} \pm 0,00$ \\
\hline
\end{tabular}
cactácea xiquexique encontram-se na tabela 1.

Tabela 1: Caracterização físico-química dos bolos elaborados com a polpa do xiquexique

Fonte: os próprios autores.

Foram constatadas diferenças estatisticamente significativas $(\mathrm{p}<0.05)$ com relação ao percentual de umidade das formulações elaboradas (Tabela 1). A formulação F1 apresentou os maiores percentuais de umidade $(39,72 \%)$, tal fato pode estar atrelado a ausência de farinha na formulação (tanto trigo como arroz) e o fato de a polpa do xiquexique apresentar elevados percentuais de água em sua composição, além disso a parte fibrosa da planta pode ter influenciado também nestes valores. Padilha et al. (2016) ao estudarem os efeitos do aproveitamento integral de banana prata na elaboração de bolo, obtiveram valores próximos 
aos reportados neste estudo. Já Rego et al. 2010, ao avaliarem um produto similar adicionado de casca de banana obteve valores superiores (49\%), resultado este que pode estar associado a quantidade de fibras existente na matéria-prima. Em formulação de um bolo de chocolate modificado (POLETTO et al. 2015) encontraram valores similares as formulações F2 e F3 respectivamente (31,2 e 20,6). Já Rios (2014) ao formular um bolo utilizando extrato de aveia obteve $38,0 \%$ de umidade, valor próximo ao encontrado neste estudo para a formulação F1.

Contraditoriamente o teor de umidade (tabela 1) foi menor a formulação adicionada de farinha de arroz (F3), visto que esta farinha apresenta uma quantidade considerável de fibras alimentares com boa capacidade de absorção de água, contudo, a adição da polpa pode ter afetado essa capacidade.

Com relação aos valores de proteínas (Tabela 1) foram observadas diferenças estatísticas $(\mathrm{p}<0.05)$ entre a formulação F2 e as formulações F1 e F3 respectivamente, o conteúdo de proteínas da formulação F2 foi superior ao das demais formulações, isso pode ser atribuído ao fato desta formulação ter sido elaborada com farinha de trigo, que em sua composição possui glúten, Cesar et al.(2006) afirmam que do conteúdo protéico total do trigo, aproximadamente $85 \%$ corresponde a gliadina (alta extensibildade) e a glutenina (alta elasticidade) responsáveis pelo glúten. Tendo em vista que as formulações F1 e F3 foram elaboradas sem a adição de trigo e com matérias-primas com baixíssimo conteúdo proteínas a diferença encontrada pode ser justificada dessa forma.

Não foram observadas diferenças estatísticas ( $p>0.05)$ com relação ao conteúdo de lipídeos, cinzas, açúcares e pH entre as três formulações. Para os valores de acidez titulável foram constatadas diferenças estatísticas $(p<0.05)$ entre a formulação $F 1$ em relação às formulações F2 e F3 (tabela 1), o valor de acidez na formulação com 100\% de polpa do xiquexique foi maior, tal fato pode ser atribuído as características próprias da cactácea.

Com relação à análise de cor, inicialmente constatou-se visualmente que a polpa da cactácea interferiu nas características de cor das formulações, este efeito pode ser observado na figura 2A, onde se observou que na formulação F1 houve uma grande participação da cor verde, fazendo com que esta diferisse drasticamente das formulações F2 e F3 (figuras 2B e 2 respectivamente. 
Figura 2: Diferença visual de cor do miolo das formulações de bolo elaboradas

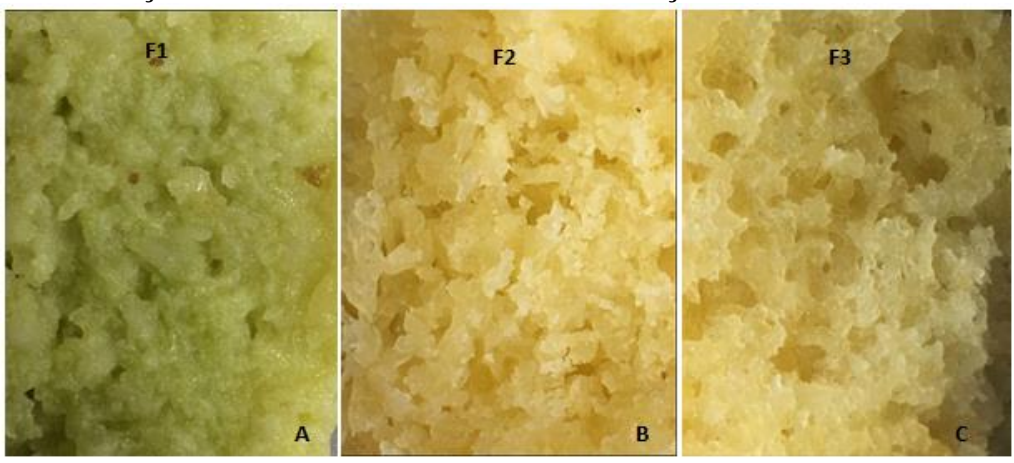

Fonte: Os próprios autores

As diferenças de cor observadas visualmente podem ser confirmadas através dos resultados mensurados objetivamente, tanto para a casca como para o miolo das formulações elaboradas conforme a tabela 2:

Tabela 2: Resultados da avaliação objetiva de cor dos bolos elaborados com a polpa do xiquexique

\begin{tabular}{|c|c|c|c|c|c|c|}
\hline & \multicolumn{6}{|l|}{ Casca } \\
\hline & $\mathrm{L}^{*}$ & $a^{*}$ & $\mathrm{~b}^{*}$ & $C^{*}$ & $\mathrm{H}^{*}$ & $\Delta \mathrm{E}$ \\
\hline & $54,23^{\mathrm{a}}$ & & & & & - \\
\hline $\mathrm{F} 1$ & 6,66 & $5,82^{\mathrm{a}} \pm 4,02$ & $29,21^{\mathrm{ab}} \pm 1,84$ & $29,96^{\mathrm{ab}} \pm 1,99$ & $78,85^{\mathrm{a}} \pm 7,67$ & \\
\hline $\mathrm{F} 2$ & $53,57^{\mathrm{a}} \pm 2,43$ & $8,68^{\mathrm{ab}} \pm 2,36$ & $32,74^{\mathrm{a}} \pm 1,74$ & $33,90^{\mathrm{a}} \pm 2,25$ & $75,27^{\mathrm{a}} \pm 3,14$ & 13,60 \\
\hline \multirow[t]{4}{*}{ F3 } & $57,72^{\mathrm{a}} \pm 1,88$ & $3,34^{\mathrm{b}} \pm 1,08$ & $26,25^{\mathrm{a}} \pm 1,93$ & $26,47^{b} \pm 2,06$ & $82,82^{\mathrm{a}} \pm 1,76$ & 14,14 \\
\hline & \multicolumn{6}{|l|}{ Miolo } \\
\hline & $\mathrm{L}^{*}$ & $a^{*}$ & $b^{*}$ & $C^{*}$ & $\mathrm{H}^{*}$ & $\Delta \mathrm{E}$ \\
\hline & & $-3,36^{\mathrm{b}}$ & & & & - \\
\hline $\mathrm{F} 1$ & $56,95^{\mathrm{b}} \pm 0,19$ & 0,14 & $23,39^{\mathrm{a}} \pm 0,26$ & $23,63^{\mathrm{a}} \pm 0,24$ & $-81,82^{\mathrm{b}} \pm 0,42$ & \\
\hline $\mathrm{F} 2$ & $62,95^{\mathrm{a}} \pm 3,18$ & $1,62^{\mathrm{a}} \pm 0,38$ & $22,57^{\mathrm{a}} \pm 1,12$ & $22,63^{\mathrm{a}} \pm 1,12$ & $85,88^{a} \pm 1,00$ & 59,64 \\
\hline F3 & $53,83^{\mathrm{b}} \pm 0,47$ & $2,15^{\mathrm{a}} \pm 0,34$ & $21,62^{\mathrm{a}} \pm 1,02$ & $21,73^{\mathrm{a}} \pm 1,04$ & $84,34^{a} \pm 0,67$ & 37,59 \\
\hline
\end{tabular}

Fonte: Os próprios autores

Na tabela 2 é possível observar que os valores do parâmetro $L^{*}$ (Luminosidade) para a casca não apresentaram diferenças estatísticas significativas ( $>>0.05)$ entre os tratamentos, enquanto que para o miolo a formulação F2 foi a que apresentou maiores valores de luminosidade. Com os valores obtidos é possível afirmar baseado na escala de 0 a 100 que tanto para a casca como para o miolo as formulações são consideradas claras, visto que apresentam valores abaixo de 50 ( $\left.\mathrm{L}^{*}<50\right)$ (COHEN; JACKIX, 2005). Vários fatores podem interferir nos parâmetros de cor dos bolos, como o tempo de forneamento, que acelera as reações de Maillard e caramelização assim como a presença de ovos e açúcares, que progressivamente aceleram o do miolo e da crosta.

Os valores de $\mathrm{a}^{*}$ tanto na crosta como no miolo (com exceção do miolo da formulação F1 que apresentou valor negativo, justificado pela tonalidade verde em virtude da adição da 
polpa), apesar de apresentarem-se positivos, mostraram-se de baixos, o que indica que as formulações apresentaram uma tendência à coloração vermelha. Em produtos forneados a cor é um importante parâmetro de qualidade, crosta e miolo demasiadamente claros ou escuros remetem a impressão de falhas durante o processamento, como temperatura elevada associada a presença de açúcares acentuam as reações de Maillard e de caramelização, levando ao seu escurecimento (ESTELLER e LANNES, 2005). A coloração marrom característica da crosta de bolos é resultante da combinação dos índices de $a^{*}$ e $b^{*}$ e resulta no índice de saturação $\mathrm{C}^{*}$, este de acordo com a tabela 2 foi apenas estatisticamente diferente $(\mathrm{p}<0.05)$ para a casca dos bolos sendo a amostra F2 a mais saturada. Com relação ao ângulo de tonalidade o miolo da amostra F1 como esperado apresentou-se estatisticamente diferente $(\mathrm{p}<0.05)$, visto que os valores encontram-se negativos, apresentando o produto uma tonalidade "esverdeada".

\section{CONCLUSÕES}

Conclui-se que a cactácea xiquexique apresenta potencial para ser utilizada na elaboração de bolos ou produtos panificáveis. O bolo com $100 \%$ da polpa do xiquexique apresentou-se mais úmido, levemente mais ácido, e com coloração característica da planta. As demais formulações com a adição de farinha de trigo (F2) e arroz (F3) apresentaram características similares, tanto na composição físico-químicas, como em sua aparência. $\mathrm{O}$ apelo do uso da farinha de arroz na elaboração do bolo é atrativo, principalmente pelo fato de poder ser consumido por pessoas portadoras da doença celíaca.

\section{REFERÊNCIAS}

ADITIVOS E INGREDIENTES. Especial Panificação. São Paulo: Insumos. 55 ed, p. 68, 2008. Disponível emhttp://insumos.com.br/aditivos_e_ingredientes/materias/85.pdfAcesso em: 24 set. 2018.

ALMEIDA, C. A. de et al. Características físicas e químicas da polpa de xiquexique. Revista Ciências Agronômica, Fortaleza, v. 38, n. 4, p.440-443, out./nov. 2007.

BORGES, J. T. da S.; PIROZI, M. R.; LUCIA S. M. D.; PEREIRA, P. C.; MORAES, B. F. e.; castro, v. c. UTILIZAÇÃO DE FARINHA MISTA DE AVEIA E TRIGO NA ELABORAÇÃO DE BOLOS. B. CEPPA, Curitiba, v. 24, n. 1, p. 145-162, jan./jun. 2006.

CANTERI, M.G., ALTHAUS, R.A., VIRGENS FILHO, J.S., GIGLIOTI, E.A., GODOY, C.V. SASM - Agri: Sistema para análise e separação de médias em experimentos agrícolas pelos métodos Scott-Knott, Tukey e Duncan. Revista Brasileira de Agrocomputação, v.1, n.2, p.18-24. 2001

CAVAlCANTI, N. de B.; RESENDE, G. M. de. Consumo de xiquexique (Pilocereus 
gounellei (A. Weber ex K. Schum.) Bly. exRowl) por caprinos no semi-árido da Bahia. Revista Caatinga, Mossoró, v. 20, n. 1, p.22-27, jan./mar. 2007.

CAVALCANTI, N. de B.; RESENDE, G. M. de. EFEITO DE DIFERENTES SUBSTRATOS NO DESENVOLVIMENTO DE MANDACARU (Cereus jamacaru P. DC.), FACHEIRO (Pilosocereus pachycladus RITTER), XIQUEXIQUE (Pilosocereus gounellei (A. WEBWR EX K. SCHUM.) BLY. EX ROWL.) E COROA-DE-FRADE (Melocactusbahiensis BRITTON \& ROSE). Revista Caatinga, Mossoró, v. 20, n. 1, p.28-35, jan./mar. 2007. UNIVERSIDADE FEDERAL RURAL DO SEMI-ÁRIDO (UFERSA).

CAVALCANTI, N. de B.; RESENDE, G. M. de. UTILIZAÇÃO DO XIQUEXIQUE (Pilocereus gounellei (A. Weber ex K. Schum.) Bly. exRowl) NA ALIMENTA ÇÃO DOS ANIMAIS. In: CONGRESSO BRASILEIRO DE AGROECOLOGIA, 4., 2006, Belo Horizonte. Construindo horizontes sustentáveis: anais. Belo Horizonte: EMATER-MG, 2006. Disponível em: http://www.alice.cnptia.embrapa.br/alice/handle/doc/132831. Acesso em 11 de set. 2018.

CESAR, Aldara. Panificios sem guten- Universidade Federal de Minas Gerais.v22 p. 150-155 março, 2008

CHAVES, E. M. F.; BARROS, R. F. M. CACTÁCEAS: RECURSO ALIMENTAR EMERGENCIAL NO SEMIÁRIDO, NORDESTE DO BRASIL. Gaia Scientia, Paraíba, v. 9, n. 2, p.129-135, 2015.

ESTELLER, M. S.; ZANCANARO JÚNIOR, O.; LANNES, S. C. da S. Bolo de "chocolate" produzido com pó de cupuaçu e kefir. Revista Brasileira de Ciências Farmacêuticas. vol. 42, n. 3, jul./set., 2006.

COHEN, K. O.; JACKIX, M. N. H. Estudo do liquor de cupuaçu. Revista Ciência e Tecnologia de Alimentos, v. 25, n. 1, 2005.

GOUVEIA, Flávia. Indústria de alimentos: no caminho da inovação e de novos produtos. Inovação Uniemp [online].Vol.2, n.5, pp. 32-37. 2006.

INSTITUTO ADOLFO LUTZ. Normas Analíticas do Instituto Adolfo Lutz. Métodos físicoquímicos para análises de alimentos. $4^{\mathrm{a}}$ ed. (1ª Edição digital), 2008. 1020 p.

LUCENA, C. M. de et al. Conhecimento local sobre cactáceas em comunidades rurais na mesorregião do sertão da Paraíba (Nordeste, Brasil). Biotemas, [s.1.], v. 25, n. 3, p.281-291, 30 ago. 2012. Universidade Federal de Santa Catarina (UFSC). http://dx.doi.org/10.5007/2175-7925.2012v25n3p281.

MOTA, M. C.; CLARETO, S. S.; AZEREDO, E. M. C.; ALMEIDA, D. M.; MORAES, A. L. L. Bolo light, diet e com alto teor de fibras: elaboração do produto utilizando polidextrose e inulina. Revista Instituto Adolfo Lutz. São Paulo, 2011;70(3):268-75.

PADILHA, Murilo et al. Caracterização físico-química de bolo com o aproveitamento integral da banana prata. In: CISDEM - FÓRUM INTERNACIONAL DE CÁTEDRA IBEROAMERICANA-

SUIZA DE DESAROLLO DE MEDICAMENTOS, Não use números Romanos ou letras, use somente números Arábicos., 2016, Cascavel - Paraná. Anais... . Cascavel: Cisdem, 2016. p. 
01

01.

Disponível

em:

<http://eventosunioeste.unioeste.br/images/cosimp/anais/pages/artigos/13647.pdf>. Acesso em: 11 ago. 2018.

PEREIRA JÚNIOR, L. R. et al. DIAGNÓSTICO SOCIOECONÔMICO E ESTRATÉGIAS DE CONVIVÊNCIA COM A SECA EM REGIÃO SEMIÁRIDO. Engenharia Ambiental, Espirito Santo do Pinhal, v. 12, n. 1, p.168-184, jan./jun. 2015.

PEREIRA, F. C.; PERREIRA, D. D.; SANTOS, G. M.; LIMA, V. L. A.; FERREIRA, R. R. S. Implantação de uma Lavoura de Xique-xique em Picuí - PB: Plantando Latas D'água no Semiárido Brasileiro (SAB). In: IX Congresso Brasileiro de Agroecologia, Diversidade e Soberania na Construção do Bem Viver, Cadernos de Agroecologia, v.10, n.3, 2015.

PINHEIRO, T. S.; FERREIRA, A. C. ESPÉCIES DE CACTACEAE NAS RESTINGAS DO NORDESTE BRASILEIRO: ASPECTOS FUNCIONAIS. Gaia Scientia, Paraíba, v. 9, n. 2, p.193-201, 2015.

POLETTO BO et al. (2015) Rev.Cient.Faculdade de Eduacação e Meio Ambiente. V.6(2):7791

REGO, F. F. A. et al. Análise da Composição centesimal do bolo da casca de Banana Prata. 194 Revista da Universidade Vale do Rio Verde, Três Corações, v. 11, n. 1, p. 185-194, jan./jul. 2013 In: CONGRESSO BRASILEIRO DE QUÍMICA, 50, 2010, Cuiabá. Anais...Rio de Janeiro: Associação Brasileira de Química, 2010.

SANTOS, J. L.; ROSSITO, P.; SANTOS, E. F.; NOVELLO, D. EFEITO DA ADIÇÃO DE INULINA EM BOLO DE BANANA: ANÁLISE FÍSICO-QUÍMICA E SENSORIAL ENTRE CRIANÇAS. Evidência, Joaçaba v. 16, n. 1, p. 31-44, jan./jun. 2016.

SCHMIELE, M.; SILVA, L. H. da.; COSTA, P. F. P. da.; RODRIGUES, R. da S.; CHANG, Y. K. NFLUÊNCIA DA ADIÇÃO DE FARINHA INTEGRAL DE AVEIA, FLOCOS DE AVEIA E ISOLADO PROTEICO DE SOJA NA QUALIDADE TECNOLÓGICA DE BOLO INGLÊS. B. CEPPA, Curitiba, v. 29, n. 1, p. 71-82, jan./jun. 2011.

SILVA, L.M.R.; ABREU, D.A.; SOARES, D.J.; PONTES, D.F.; CONSTANT, P.B.L. Processamento de bolo com farinha de quinoa (chenopodium quinoa willd): Estudo de aceitabilidade.Revista Brasileira de Produtos Agroindustriais, Campina Grande, v.12, n.2, p.125 - 132, 2010.

SILVA, Valdeline A. DIVERSIDADE DE USO DAS CACTÁCEAS NO NORDESTE DO BRASIL: UMA REVISÃO. Gaia Scientia, Paraíba, v. 9, n. 2, p.137-154, 2015 